\section{EFCC}

2,1

\section{2}

Received 26 September 2020 Revised 31 October 2020 Accepted 1 November 2020

\section{Gender and class distinction in travel behavior: evidence from India}

\author{
Taru Saigal, Arun Kr. Vaish and N.V. Muralidhar Rao \\ Department of Economics and Finance, Birla Institute of Technology and Science, \\ Pilani, India
}

\begin{abstract}
Purpose - This paper aims to examine the gender differences in various measures of travel behavior for a large-sized Indian city, taking into account the existing class differences.

Design/methodology/approach - Stratified random sampling technique is used to collect primary data for travel behavior. The collected data is then differentiated on the basis of socioeconomic characteristics and gender. Descriptive statistics are used for analysis.

Findings - The findings confirm that, women mostly walk and men use motorized vehicles. With an improvement in socioeconomic status, women switch over to public transport and men continue to ride motorized vehicles. While the number of women making everyday trips declines with a rise in socioeconomic status, the number of men rises.

Research limitations/implications - The study points out at the need for development of an adequate infrastructure of nonmotorized transport and public transport in the city which attends to not only the issue of environmental quality but also of women's empowerment.

Originality/value - To the best of the authors' knowledge, this is the first time a comprehensive analysis of differences in travel behavior between men and women on the basis of socioeconomic status is carried out in this region. This analysis will facilitate the policy makers in understanding the inconsistencies in transport demand between the two groups of population.
\end{abstract}

Keywords Gender, Carbon footprint, Women empowerment, Developing country, Socioeconomic status, Travel behavior, Large-sized city

Paper type Research paper

\section{Background}

Mobility is pivotal to women's empowerment (Mahadevia, 2015). It not only helps women in accessing opportunities but also challenges restrictions imposed by all-pervading patriarchy. However, a lack of affordable and convenient transport option is a big turn down in achieving these goals. Gender also influences mobility. In India, where two-wheelers frame an important constituent of privately owned vehicles, there are far few women users of them (Mahadevia and Advani, 2016). Women, around the globe, display a similar low transport demand and thereby contribute much lower to environmental footprint than men (Xiao and McCright, 2015). Gender and mobility, therefore, share a bilateral relationship (Hanson, 2010).

(C) Taru Saigal, Arun Kr. Vaish and N.V. Muralidhar Rao. Published in Ecofeminism and Climate Change. Published by Emerald Publishing Limited. This article is published under the Creative Commons Attribution (CC BY 4.0) licence. Anyone may reproduce, distribute, translate and create derivative works of this article (for both commercial and non-commercial purposes), subject to full attribution to the original publication and authors. The full terms of this licence maybe seen at http:// creativecommons.org/licences/by/4.0/legalcode 
Gender differences in travel behavior have been drawing the attention of researchers lately. A study conducted in the developed cities of Auckland, Dublin, Helsinki, and Lisbon confirms the role of gender in travel behavior ( $\mathrm{Ng}$ and Acker, 2018). Women are less cardependent in cities in Belgium (Vos and Alemi, 2020) and Serbia (Simićević et al., 2016), and majorly use them as passengers in Israel (Elias et al., 2015). Related recent literature in the developing economies are few. Similar to the findings of the developed world, findings in developing regions of Novi Sad (Basarić et al., 2016), Hanoi, Jakarta, Kuala Lumpur, Manila (Ng and Acker, 2018), and Suzhou (Yang et al., 2013) also confirm that women travel shorter

Gender and class distinction distances, prefer public transport, walking or cycling over cars. Studies focusing on gender disparities in travel behavior in India also confirm women's travel distances to be shorter, their lower dependence on motorized vehicles, and lower trip rates as compared to men (Jain and Tiwari, 2020; Mahadevia and Advani, 2016; Saigal et al., 2020).

Few studies discuss the interrelationship between gender, income and travel behavior. In Pune, irrespective of their income class, men have a greater dependence on motorized vehicles and women of only high-income groups use two-wheelers (Astrop et al., 1996). With increase in income, women shift to public transport and men to motorized vehicles in Rajkot (Mahadevia and Advani, 2016).

Literature hints at inconsistencies in different measures of travel pattern between men and women existing globally. This study aims to examine the gender disparities in travel behavior amid different socioeconomic classes in a large-sized Indian city. A deprivation of an analysis of the kind not only omits the acknowledgement of the least polluting sex and group but also leads to a gradual rise in carbon footprint per person. The study highlights the need for development of an adequate infrastructure of public transport and nonmotorized transport in the city. This will address the issue of environmental quality and women empowerment.

The objective of this paper is to explore gender disparities in measures of travel behavior segregated on the basis of different socioeconomic groups in a developing country city; and to examine gender differences in share of various modes of transport in different distance categories. This paper reaffirms the travel behavior of women and men observed globally.

\begin{abstract}
About Jaipur
Jaipur, which is the capital city of a north Indian state, is the tenth most populous city in the country. It has a sex ratio of 900 and an average literacy rate of $83.33 \%$ (Census of India, 2011).

Jaipur City Transport Services Limited of Rajasthan State Road Transport Corporation operates more than 400 regular and low-floor city buses. The total number of city buses, both government and private, in 2007 was 327 (Wilbur Smith and MoUD, 200816). Approximately $72 \%$ of the roads in the city do not have a footpath. The remaining roads where footpaths exist are mostly parked with vehicles (Times of India, 2019). Though Jaipur Metro has commenced its operation in the city, our study finds limited use of the same. While the use of bicycle is minimal in the city, that of motorized two-wheelers is abundant and frequent.
\end{abstract}

\title{
Data and methodology
}

A sample proportionate to each of the eight zones into which Jaipur Municipal Corporation is divided is used. It comprises 600 individuals stratified on the basis of sex ratio and average literacy rate in the city. Each individual who is a part of the sample is between the age of 18 and 60 years. Data on socioeconomic characteristics, asset ownership of the household and individual information was collected from each individual. 
EFCC

2,1

44

The study defines a trip as a one-way intra-city trip made within the boundaries of the city. Access and egress trips are considered part of the main trip. The mode of transport used to travel the longest distance within the trip is considered the mode of the whole trip.

We also differentiate between the usage of motorized vehicles as a driver and as a passenger.

We categorize the individuals comprising the sample into three socio-economic groups using monthly per capita consumption expenditure. Three mutually exclusive categories, namely, SEG1, SEG2 and SEG3 have been created using cut-off points for monthly per capita consumption expenditure as Q1 and Q3 values. In cases where the data for consumption expenditure was missing, which are approximately $6 \%$ of the database, we use house ownership and house type as a proxy. We define the socio-economic groups as follows.

SEG1: This category represents individuals belonging to low socio-economic background with monthly per capita consumption expenditure $\leq$ INR 2500. In case of missing values for consumption expenditure, individuals whose household lives in houses which they have occupied without paying for any rent or own a kutcha house are adjusted in SEG1.

SEG2: This group depicts middle socio-economic background with monthly per capita consumption expenditure between INR 2501-INR 7000. Ownership of semi-pucca houses or where the household lives in rented houses are considered in SEG2, in case of missing data.

SEG3: This category represents high socio-economic background of individuals with monthly per capita consumption expenditure $>$ INR 7000. For missing values, individuals whose household owns a pucca house are considered to be a part of SEG3.

This study has the following limitations:

- It does not take into account the actual per capita income values for calculating the socio-economic categories.

- It fails to evaluate the per capita trip rates in the city which capture the average of total number of trips performed by an inhabitant in a day.

- The study also does not differentiate between different types of public transport used in the city, such as buses, autorickshaws, etc.

\section{Travel behavior adjusted by gender and class in Jaipur}

The entire population is not making a trip daily. Table 1 shows that only $65 \%$ female and $87 \%$ male make a trip every day. However, with an improvement in the socioeconomic status, fewer women and more men tend to make a trip daily. Mahadevia (2012) finds that with an increase in family income, women are likely to shift out of the labor force in India,

Table 1 .

Trip incidence and trip length by socioeconomic groups and sex

\begin{tabular}{lcccr}
\hline & \multicolumn{2}{c}{ \% of total population making a trip daily } & \multicolumn{2}{c}{ Most frequently travelled distance } \\
Socio-economic group & Female & Male & Female & Male \\
\hline SEG 1 & 54.05 & 80.41 & $0-5 \mathrm{~km}$ & $0-5 \mathrm{~km}$ \\
SEG 2 & 73.29 & 90.07 & $0-5 \mathrm{~km}$ & $0-5 \mathrm{~km}$ \\
SEG 3 & 61.11 & 90.48 & $0-5 \mathrm{~km}$ & $5-15 \mathrm{~km}$ \\
Total & 65.41 & 87.27 & $0-5 \mathrm{~km}$ & $0-5 \mathrm{~km}$ \\
Source: Primary survey & & & & \\
\hline
\end{tabular}


thereby declining the need to make a trip every day. Workforce participation is the major cause of everyday trips.

Majority of the population in Jaipur travels short distances of not more than $5 \mathrm{~km}$. On an average there exists no gender discrimination in this. The reason why women usually travel short distances can be due to the existence of gender differences in access to owned vehicles and feminization of responsibilities within a household (Mahadevia and Advani, 2016).

Table 2 shows gender and class difference in modal share. On the whole, the most commonly used mode of transport by women is walking whereas that by men is motorized two-wheeler as a driver. This trend is observed in SEG1 as well as SEG2. In SEG3 women shift to using public transport as the most commonly used mode of transport while men still prefer driving the motorized two-wheelers. The proportion of women drivers of motorized two-wheelers increases with an improvement in socioeconomic class. The overall use of motorized four-wheelers is low irrespective of the socioeconomic groups. We observe increase in the percentage of men driving four-wheelers, with the highest percentage in SEG3. One of the positive changes worth noticing here is the swap in the percentage of women as drivers and women as passengers of four-wheelers in SEG3. While $11 \%$ of women drive, $7 \%$ use four-wheelers as passengers. There also exists gender difference in the use of public transport irrespective of the socioeconomic class with continuous decline in the percentage of men users as the socioeconomic class improves. The ratio of female to male in use of public transport is low in SEG1 at 1.14, increases slightly in SEG2 at 1.28 and is the highest in SEG3 at 2.05. The maximum usage of hired taxis is made by women belonging to SEG3.

Women usually prefer to walk or take public transport. Cycling is not an option they consider. This can be attributed to cultural factors such as their clothing type (Mahadevia and Advani, 2016).

Figures 1 and 2 reveal that the most commonly used mode of transport for different distance categories for men and women. It is evident that women prefer to walk for short distances and take public transport for long distances as against men who prefer driving motorized vehicles for even short distances and switch to public transport only in case of very long distances.

\begin{tabular}{|c|c|c|c|c|c|c|c|c|}
\hline \multirow[b]{2}{*}{ Mode } & \multicolumn{2}{|c|}{ SEG1 } & \multicolumn{2}{|c|}{ SEG2 } & \multicolumn{2}{|c|}{ SEG3 } & \multicolumn{2}{|c|}{ All } \\
\hline & Female & Male & Female & Male & Female & Male & Female & Male \\
\hline Valking & 57.14 & 22.34 & 46.53 & 11.03 & 14.08 & 11.39 & 41.05 & 14.56 \\
\hline Bicycle & 0 & 6.38 & 0 & 2.21 & 0 & 0 & 0 & 2.91 \\
\hline $\begin{array}{l}\text { Motorized two-wheeler as } \\
\text { a driver } \\
\text { Motorized two-wheeler as }\end{array}$ & 5.71 & 38.30 & 19.44 & 55.88 & 25.35 & 48.10 & 17.54 & 48.54 \\
\hline $\begin{array}{l}\text { a passenger } \\
\text { Motorized four-wheeler as }\end{array}$ & 2.86 & 1.06 & 5.56 & 0.74 & 2.82 & 0 & 4.21 & 0.65 \\
\hline $\begin{array}{l}\text { a driver } \\
\text { Motorized four-wheeler as }\end{array}$ & 0 & 4.25 & 0 & 8.82 & 11.27 & 20.25 & 2.81 & 10.36 \\
\hline a passenge & 2.86 & 0 & 1.3 & 0 & 7.04 & 1.27 & 3.16 & 0.32 \\
\hline $\begin{array}{l}\text { Tractors } \\
\text { Public transport (Bus/ }\end{array}$ & 0 & 0 & 0 & 0.74 & 0 & 0 & 0 & 0.3 \\
\hline Autoricksh & 31.43 & 27.66 & 26.39 & 20.59 & 33.8 & 16.46 & 29.47 & 21.68 \\
\hline ull-fare) & 0 & 0 & 0.69 & 0 & 5.63 & 2.53 & 1.75 & 0.6 \\
\hline Metro & 0 & 0 & 0 & 0 & 0 & 0 & 0 & 0 \\
\hline Total & 100 & 100 & 100 & 100 & 100 & 100 & 100 & 100 \\
\hline
\end{tabular}

Source: Primary survey

Gender and class distinction

45 


\section{EFCC}

2,1

46

Figure 1.

Modal share by trip length for male
Figure 2.

Modal share by trip length for female

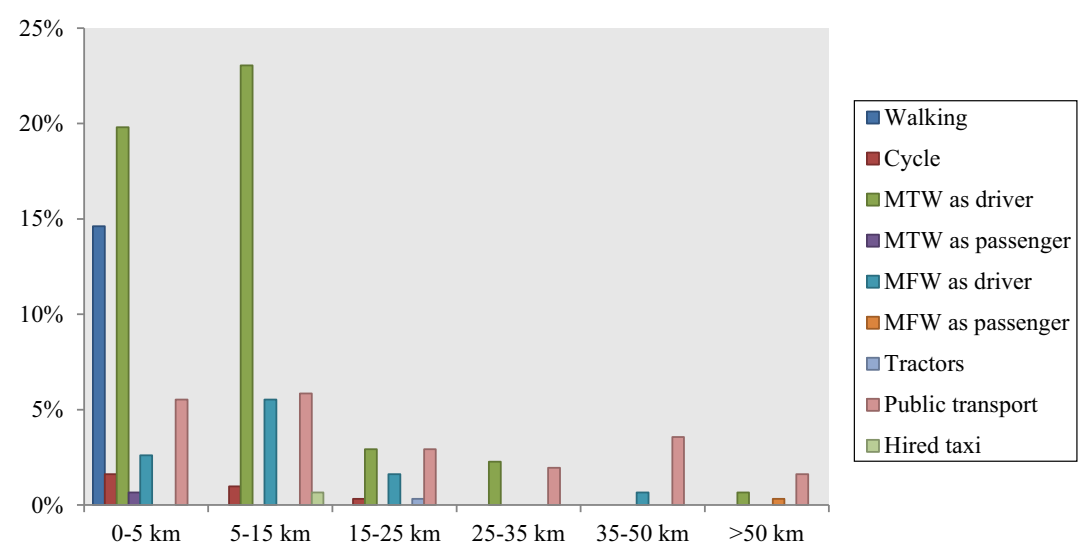

Notes: MTW= Motorized Two-Wheeler; MFW= Motorized Four-Wheeler

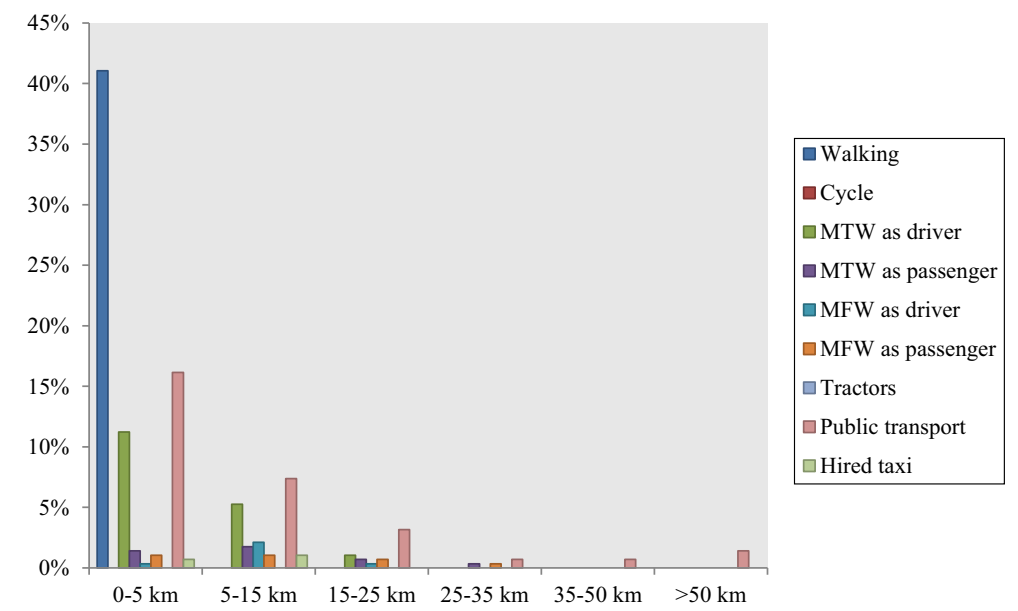

Notes: MTW= Motorized Two-Wheeler; MFW= Motorized Four-Wheeler

Three quarters of men made a trip to work every day as against two-fifths of women (Table 3). The other purpose for which both men and women make trip every day is involvement in religious activities. The highest proportion of population making a daily trip for the purpose of education is that of women belonging to SEG2.

\section{Discussion}

Analysis of the collected data shows that, in the study area, the complete population does not make a trip every day (Mahadevia and Advani, 2016), people usually travel short distances, and women mostly walk and men use motorized vehicles (Li et al., 2018; Mahadevia and Advani, 2016). With an improvement in the socioeconomic status, lesser women and more men make an every day trip, women switch over to public transport and men continue to ride motorized vehicles (Mahadevia and Advani, 2016). 


\begin{tabular}{|c|c|c|c|c|c|c|c|c|c|}
\hline \multirow[b]{2}{*}{ Purpose } & \multicolumn{2}{|c|}{ SEG1 } & \multicolumn{2}{|c|}{ SEG2 } & \multicolumn{2}{|c|}{ SEG3 } & \multicolumn{2}{|c|}{ All } & \\
\hline & Female & Male & Female & Male & Female & Male & Female & Male & clas \\
\hline Work & 40.54 & 71.13 & 37.67 & 80.14 & 45.83 & 71.43 & 40.41 & 75.16 & \\
\hline Education & 12.16 & 7.22 & 15.75 & 9.65 & 11.11 & 9.93 & 13.70 & 9.94 & \\
\hline Health & 0 & 0 & 0.68 & 0 & 0 & 0 & 0.34 & 0 & \\
\hline Shopping & 2.70 & 2.06 & 4.11 & 5.67 & 1.39 & 1.19 & 3.08 & 3.42 & \\
\hline Pick-up/Drop-off & 4.05 & 13.40 & 9.59 & 12.06 & 8.33 & 4.76 & 7.88 & 10.56 & 7 \\
\hline Eat-out & 0 & 1.03 & 0 & 6.38 & 2.78 & 7.14 & 0.69 & 4.97 & \\
\hline Visiting relatives and friends & 2.70 & 4.12 & 3.42 & 5.67 & 6.94 & 7.14 & 4.11 & 5.59 & \\
\hline Religious activities & 21.62 & 34.02 & 37.67 & 40.43 & 22.22 & 19.05 & 29.79 & 32.92 & \\
\hline Sports/ recreation & 1.35 & 1.03 & 2.74 & 0.71 & 2.78 & 4.76 & 2.40 & 1.24 & $\begin{array}{l}\text { Daily trips by purpo } \\
\text { by socioecono }\end{array}$ \\
\hline Source: Primary survey & & & & & & & & & \\
\hline
\end{tabular}

\section{Conclusion and policy implications}

This paper explores the class and gender differences in travel behavior in a developing country city. While there exists a significant amount of literature on the topic in the developed world, similar studies for developing countries, especially India, are only few. The findings of our study reaffirm the existing gender and class differences for a large-size developing country city. It also reasserts the global propositions of women having a lower carbon footprint as compared to men. The findings call attention to the need to address varying demands of different groups of population, based on their socioeconomic status and gender, while formulating policies promoting efficient system of transportation in the city.

Empowerment of women is generally measured in terms of the level of educational attainment, receiving adequate health facilities, level of financial independence, ability to make independent decisions, freedom of movement among others. However, mobility, which is influenced by an effective transportation system, is a factor which influences all other indicators of women empowerment. Because women heavily depend on walking or using the public transport, this study points out at the need for an adequate walking infrastructure in the city along with safer and secured public transportation services. The demand for expansion of such facilities also caters to the need of curtailing greenhouse gases emissions in the city.

\section{References}

Astrop, A., Palmner, C. and Maunder, D. (1996), "The urban travel behaviour and constraints of low income households and females in Pune", Paper presented at the National Conference on Women's Travel Issues, 23-26 October, Baltimore, MD, available at: http://transport-links.com/ wp-content/uploads/2019/11/PA3206_1996.pdf (accessed 30 October 2020).

Basarić, V., Vujičić, A., Simić, J.M., Bogdanović, V. and Saulić, N. (2016), "Gender and age differences in the travel behavior- a novi sad case study", Transportation Research Procedia, Vol. 14, pp. 4324-4333.

Census of India (2011), “Jaipur city census 2011 data”, available at: www.census2011.co.in/census/city/ 77-jaipur.html (accessed 30 October 2020).

Elias, W., Benjamin, J. and Shiftan, Y. (2015), "Gender differences in activity and travel behavior in the arab world", Transport Policy, Vol. 44, pp. 19-27.

Hanson, S. (2010), "Gender and mobility: new approaches for informing sustainability", Gender, Place and Culture, Vol. 17 No. 1, pp. 5-23. 
EFCC 2,1

Jain, D. and Tiwari, G. (2020), "Gender and income based variability in travel choices in Vishakhaptnam, India", Transportation Research Procedia, Vol. 48, pp. 2870-2890.

Li, J., Lo, K. and Guo, M. (2018), "Do socio-economic characteristics affect travel behavior? A comparative study of low-carbon and non-low-carbon shopping travel in Shenyang city, China”, International Journal of Environmental Research and Public Health, Vol. 15 No. 7, pp. 1-11.

Mahadevia, D. (2012), "Decent work in Ahmedabad: an integrated approach", Working paper, ILO, DWT for South Asia and country office for India.

Mahadevia, D. (2015), "Gender sensitive transport planning for cities in India”, available at: https:// smartnet.niua.org/sites/default/files/resources/UNEP_Gender_Report_For_Upload_Med_Rez.pdf (accessed 30 October 2020).

Mahadevia, D. and Advani, D. (2016), "Gender differentials in travel pattern- the case of a mid-sized city, Rajkot, India”, Transportation Research Part D: Transport and Environment, Vol. 44, pp. 292-302.

Ng, W.-S. and Acker, A. (2018), "Understanding urban travel behaviour by gender for efficient and equitable transport policies", available at: www.itf-oecd.org/sites/default/files/docs/urban-travelbehaviour-gender.pdf(accessed 30 October 2020).

Saigal, T., Vaish, A.K. and Rao, N.V. (2020), "Intersection of gender with area and occupation in analysing travel behaviour: a case of Rajasthan, India”, EPRA International Journal of Multidisciplinary Research, Vol. 6 No. 9, pp. 237-245.

Simićević, J., Milosavljević, N. and Djoric, V. (2016), "Gender differences in travel behaviour and willingness to adopt sustainable behaviour", Transportation Planning and Technology, Vol. 39 No. 5, pp. 527-537.

Times of India (2019), “72\% Of city roads devoid of footpath: study”, 14 January.

Vos, J.D. and Alemi, F. (2020), "Are young adults car-loving urbanites? Comparing young and older adults' residential location choice, travel behavior and attitudes”, Transportation Research Part A, Vol. 132, pp. 986-998.

Wilbur Smith Associates and Ministry of Urban Development (2008), "Study on traffic and transportation policies and strategies in urban areas in India".

Xiao, C. and McCright, A.M. (2015), "Gender differences in environmental concern: revisiting the institutional trust hypothesis in the USA", Environment and Behavior, Vol. 47 No. 1, pp. 17-37, doi: 10.1177/0013916513491571.

Yang, M., Li, D., Wang, W., Zhao, J. and Chen, X. (2013), "Modeling gender-based differences in mode choice considering time-use pattern: analysis of bicycle, public transit, and car use in Suzhou, China", Advances in Mechanical Engineering, pp. 1-11.

\section{Corresponding author}

Taru Saigal can be contacted at: tarusaigal21@gmail.com

For instructions on how to order reprints of this article, please visit our website: 